\title{
BEHANDLINGSEFFEKTER INOM RÄTTSVÄSENDET - EN META-ANALYS AV MODERN NORDISK EMPIRISK FORSKNING
}

\section{Av Erik Grevholm och Eckart KÜHLhorN}

\section{INLEDNING}

Har behandlingen av dömda någon effekt? Går det att belägga att behandling inom rättsväsendet verkligen påverkar tendensen till återfall $i$ brott? Begreppet behandling syftar här på alla åtgärder som följer av en fällande dom, det vill säga såväl uttryckliga behandlingsinsatser som själva påföljden som sådan. Den vetenskapliga debatten kring dessa frågor har länge varit intensiv, inte minst i detta forum (se t.ex. Bondeson, 1986; 1987a ; 1987b; Kühlhorn, 1987a; 1987b). I föreliggande artikel presenteras en meta-analytisk genomgång av empiriska studier av effekter av behandling som har producerats i Norden mellan åren 1980 och 1995.

\section{BEHANDLINGSTANKEN}

Debatten om behandlingseffekter reflekterar en motsättning mellan anhängare av den så kallade behandlingstanken och företrädare för den nyklassiska skolan. Behandlingstankens försvarare betonar vikten av att påföljden anpassas till den dömdes behov av behandling. Rehabiliterande insatser antas kunna reducera brottslingens framtida återfallsbenägenhet. Behandlingstanken fokuserar alltså i första hand på individualprevention i form av vård. Däremot tillskrivs övriga individualpreventiva aspekter, inkapacitering och avskräckning, samt allmänpreventiva åtgärder, mindre betydelse (se t.ex. BR $\AA$-rapport, 1977:7; Kühlhorn, 1986). Den behandlingsorienterade skolan har under efterkrigstiden utövat ett betydande inflytande vid utformningen och tillämpningen av de nordiska påföljdssystemen (a.a.). I Sverige avspeglas detta bl.a. i användandet av icke tidsbegränsade rättsliga reaktioner, t.ex. det i dag avskaffade interneringsstraffet, samt $i$ tillämpningen av $\S 34$-institutet om vistelser utanför kriminalvårdsanstalt.

Behandlingsidéerna har återkommande utsatts för kritik. Företrädare för den nyklassiska rättsfilosofin framhåller exempelvis att koncentrationen på enskilda brottslingars behov kan leda till bristande proportionalitet mellan brott och straff. Detta befaras kunna minska påföljdssystemets allmänpreventiva potential. Preferensen för tidsobestämda påföljder anses även kunna utgöra ett hot mot rättssäkerheten eftersom strafftiden då bestäms av vårdansvariga i stället för att avgöras i domstol. Nyklassiska tankegångar har, inte minst i Sverige, fått ett ökat genomslag under senare år (se t.ex. BRA-rapport, 1977:7; SOU 1986:15; SOU 1995:91). Därtill råder det betydande osäkerhet om behandlingsansträngningarna verkligen genererar några rehabiliterande effekter. Kombinationen av tvivel och förhoppningar har gett upphov till en ansenlig mängd forskning. Runt om i världen har forskare försökt att utröna om behandling av avvikande beteende verkligen fungerar i samband med straffrättsliga reaktioner. 


\section{BEHOVET AV FORSKNING}

Inom olika samhällssektorer går det att skönja ett ökande intresse för att utvärdera vilka effekter som olika insatser har. Ett område som blivit föremål för omfattande empirisk forskning är vården av alkohol- och narkotikamissbrukare. På ett generellt plan framstår det som svårt att sammankoppla dessa vårdinsatser med önskvärda effekter på framtida missbruk (Bergmark \& Oscarsson, 1993). Enskilda behandlingsformer har dock i vissa fall visat sig vara effektiva. Svenska studier visar exempelvis att metadonbehandling av opiatmissbrukare har en rad positiva effekter (Gunne \& Grönbladh, 1980; Grönbladh \& Gunne, 1989; Grönbladh, m.fl. 1990). En engelsk undersökning tyder också på att denna form av behandling minskar missbrukarnas kriminella aktivitet (Parkèr \& Kirby, 1996).

Det framstår som mycket väsentligt att det bedrivs forskning kring effekter av behandling inom rättsväsendet. Eftersom straffen ofta inbegriper allvarliga ingrepp i den personliga integriteten är det angeläget att söka insikter i vilka effekter som åtgärderna har på de dömda. Vidare är det viktigt att förbättra beslutsunderlaget för utformningen och tillämpningen av påföljdssystemet. Detta kräver kunskaper i vilka effekter som olika insatser egentligen har. Samtidigt är det viktigt att konstatera att vårdinsatser gentemot brottslingar kan ha ett egenvärde utöver dess eventuella brottsreducerande effekter. Det kan exempelvis uppfattas som obarmhärtigt att inte åtminstone försöka hjälpa kriminella personer att leva ett laglydigt liv. Det kan också finnas icke legitima skäl till att behandlingsverksamheter försvaras. Behandlingsinsatser kan vara ett sätt för personer i maktställning att visa handlingskraft. Företrädare för de myndigheter som bedriver verksamheterna kan också, för sitt eget välbefinnande, vara beroende av att även ineffektiva eller rent av förkastliga verksamheter praktiseras. Det framstår vidare som speciellt viktigt att gå i genom modern nordisk behandlingsforskning eftersom detta område inte blivit föremål för en systematisk översyn under senare år.

\section{EFFEKTER}

Det viktigaste syftet med behandling inom rättsväsendet är att uppnå en minskning av återfallsbrottsligheten. Därav följer att återfall i brott är den mest centrala effektvariabeln vid behandlingsstudier. I denna artikel fokuseras i första hand på om de dömda återfallit eller ej. Andra återfallsdimensioner, t.ex. tid till första återfall samt hur allvarliga återfallsbrotten är, studeras ej. Effektfaktorerna sysselsättningsnivå och missbruk förekommer i en av de uppmärksammade studierna.

Mätningarna av återfall i brott baseras vanligen på uppgifter i olika myndighetsregister. I fråga om mätperịodernas utsträckning antas att det är möjligt att på ett tillräckligt rättvisande sätt studera återfall inom ett till två år efter behandlingen (Kühlhorn, 1974; Lennéer-Axelson \& Thylefors, 1969). Den dolda kriminaliteten, även kallat mörkertalet, är ofta ett problem i samband med brottsforskning. Bedömningen är dock att mörkertalet vanligtvis inte innebär att återfall i brott är en missvisande effektindikator vid behandlingsstudier: Något större generell osäkerhet gäller 
effektfaktorerna sysselsättningsnivå och återfall i missbruk eftersom denna typ av data sällan baseras på tillförlitliga registeruppgifter.

\section{TIDIGARE META-ANALYSER}

Under årens lopp har det gjorts återkommande försök att sammanfatta kunskapsläget inom den kriminologiska behandlingsforskningen. En av de mest kända metastudierna presenterades i mitten av sjuttiotalet av Lipton och dennes kollegor (Lipton, m.fl. 1975). Utifrån en genomgång och reanalys av 231 empiriska undersökningar som publicerats mellan åren 1945 och 1968 blev slutsatsen att de fokuserade inverventionerna endast sällan kunde knytas till konstaterbara effekter på återfall i brott eller missbruk. Detta portalverk har följts av flera liknande initiativ, varav endast några av de mest betydelsefulla kommer att nämnas här. Kyvsgaard (1978) genomförde en inventering av ett stort antal behandlingsutvärderingar som publicerats mellan åren 1960 och 1976. Även i detta fall konstaterades att behandlingsinsatserna endast i mycket begränsad utsträckning kunde knytas till positiva resultat. Whitehead och Lab (1989) menar att deras statistiska meta-analys av studier som publicerats mellan år 1975 och 1984 bekräftar tidigare slutsatser om att behandlingsåtgärderna inte tycks ha någon positiv effekt på recidivismen bland dömda ungdomar. Utifrån en statistisk meta-analys menar däremot Andrews m.fl. (1990) att speciella behandlingsinsatser har betydande reducerande effekter på såväl ungdomars som vuxnas benägenhet att återfalla i brott. Lipsey (1992) anser att behandling visats sig generera positiva effekter på ungdomsbrottslingar. Slutsatsen baseras på en genomgång av 443 studier som publicerats från år 1950 och framåt. Samtidigt noteras att metodologiska skillnader mellan studierna samt forskarnas grad av delaktighet i behandlingen står för en avsevärd del av variationen beträffande uppmätta effekter.

I detta sammanhang är det inte möjligt att mer ingående bedöma de kommenterade studierna. Klart är emellertid att resultaten pekar åt olika håll och att medodologiska problem är en återkommande källa till osäkerhet. Det faktum att hittills genomförda inventeringar redovisar allt från fullständig verkningslöshet till påtagliga effekter aktualiserar behovet av en uppdaterad sammanställning av det befintliga forskningsläget.

Liptons forskarlag arbetar med en uppföljning av den tidigare studien som bygger på en totalinventering av den behandlingsforskning som producerats från år 1968 till år 1994. Författarna till denna artikel har fungerat som det amerikanska initiativets nordiska representanter i arbetet att bedöma, samla in och koda de nordiska studier som ska ingå i sammanställningen. Bedömningarna gäller i första hand om studierna ska inkluderas i meta-analysen men påverkar endast i liten utsträckning kodningsarbetet. Vid sidan av föreliggande alster kommer samarbetet att resultera i en rapport från det svenska Brottsförebyggande rådet samt senare även i en statistisk meta-analys av befintliga nordiska undersökningar. 


\section{URVALSKRAV}

De metodologiska urvalskriterier som tillämpats i detta delprojekt är identiska med de krav som gäller i det övergripande amerikanska forskningsprojektet (se Pearson, m.fl. 1996). Det första kravet är att angreppssättet har en kvantitativ inriktning som möjliggör bearbetning av statistiska uppgifter. Det andra kravet är att uppläggningen har en experimentell inriktning som helst bör inbegripa jämförelser med någon form av kontrollgrupp. Om designen inte inkluderar någon kontrollgrupp måste det finnas förutsättningar för jämförelser mellan ekvivalenta för- och eftermätningar. Det tredje kravet är att rapporten måste innehålla elementära beskrivningar av antalet respondenter, urvalsförfarande, mätinstrument och helst även av själva behandlingen. Den sistnämnda typen av uppgifter är viktiga för bedömningen av studien samt för att det ska vara möjligt att reproducera både behandlingen och undersökningen av den. Dessa kriterier ska ses som en elimineringsmekanism i syfte att skilja uppenbart otillräckliga studier från potentiellt vederhäftiga arbeten.

\section{INSAMLING}

Arbetet med att identifiera studier som skulle kunna vara aktuella för att ingå i metaanalysen har inbegripit konsultationer med nyckelpersoner runt om i Norden som besitter betydande kunskaper om behandlingsforskning, bl.a. Kauko Aromaa i Finland, Ulla Bondeson och Britta Kyvsgaard i Danmark, Yngve Hammerlin i Norge och Hildigunnur Ólafsdóttir i Island. Vidare har skriftliga förfrågningar sänts till cirka femtio nordiska forskningsinstutitioner. Dessa åtgärder har kompletterats med sökningar i nordiska och internationella databaser samt manuella sökningar utifrån litteraturförteckningar. Ett femtiotal studier har granskats under arbetets gång. Endast en bråkdel av dessa ingår i meta-analysen. Inledningsvis sållades de undersökningar bort som inte motsvarade den övergripande ram som omgärdar detta delprojekt. Därefter matchades de återstående undersökningarna mot de metodologiska urvalskraven.

\section{FORSKNINGSDESIGNER}

Effekter av behandling studeras bäst med hjälp av experimentellt inspirerade metoder (se t.ex. Campbell, 1975). Experimentellt inriktade uppläggningar brukar delas in i sant experimentella, kvasiexperimentella och preexperimentella angreppssätt (Nachmias \& Nachmias, 1991). I modern nordisk behandlingsforskning har endast den svagaste kategorin av uppläggningar använts, det vill säga preexperimentella designer.

Den vanligaste uppläggningen är The static-group comparison (statisk kontrollgruppsdesign) (Campbell \& Stanley, 1963). Denna design inbegriper jämförelser av eftermätningar mellan en experimentgrupp och en kontrollgrupp, som inte bildats utifrån en slumpmässig procedur eller med hjälp av matchning. Eftersom uppläggningen vanligtvis medger liten kontroll av tänkbara alternativa förklaringar och felkällor så tillhör den de svagaste angreppssätten om syftet är att estimera effekter. 
En annan relativt vanligt förekommande design är The static group comparison with ex post facto matching (matchad kontrollgruppsdesign) (a.a). Experimentgruppen jämförs här efter behandlingen med en kontrollgrupp som bildats genom matchning. Denna typ av design är också en relativt svag metod för att påvisa effekter av behandling. Tillförlitligheten är helt beroende av att matchningen kan hantera konkurrerande förklaringar.

I ett fall används The one-group pretest-posttest design (endast för- och eftermätning) som endast bygger på för- och eftermätning av en undersökningsgrupp (a.a). Eftersom designen inte inbegriper jämförelser med någon kontrollgrupp är möjligheterna att utesluta andra tolkningar mycket begränsade. Metoden är den minst trovärdiga när effekter av behandling studeras.

I syfte att förstärka de i grunden svaga uppläggningarna kompletteras prövningarna i några fall med olika former av multivariat analys. Sådana analyser kan stärka i övrigt svaga angreppssätt. Vanligtvis lyckas man dock inte kontrollera för de mest framträdande felkällorna med hjälp av dessa metoder.

\section{RESULTAT}

Endast elva nordiska behandlingsstudier motsvarar de grundläggande kraven. Tio av dessa är svenska och en har norskt ursprung. Sex av studierna berör effekter av kriminalvård. Fyra undersökningar handlar om effekter av rättspsykiatrisk vård. En studie fokuserar på effekter av institutionsbaserad tvångsvård av ungdomar.

Alla de i detalj granskade studierna är behäftade med metodologiska brister och tillkortakommanden i delar som berör effektestimering. I två fall går det trots detta att sätta viss tilltro till resultaten. Den norska studien av Danielsen och Hammerlin (1995) är inte metodologiskt acceptabel. Men det redovisade nollresultatet framstår som rimligt med tanke på den studerade behandlingens begränsade potentiella genomslagskraft (behandlingen omfattade blott två dagar) samt att den mest framträdande metodbristen, selektion av motivation (se t.ex. Campbell \& Stanley, 1963) bör ha stimulerat ett överdrivet positivt utfall. I Ahlbergs studie (1984) av interneringsstraffet är slutsatsen att straffet inte tycktes ha någon inverkan på återfallsbenägenheten jämfört med sedvanlig fängelsepåföljd. Två omständigheter gör att slutsatsen framstår som trovärdig trots de förekommande metodologiska svagheterna. Effekten skattas med kriterieanalyser i form av diskriminantanalyser (se t.ex. Mannheim \& Wilkins, 1955). Därmed kompenserar prövningen delvis för att de jämförda grupperna inte var helt jämförbara innan bestraffningen. Vidare framgår det att behandlingsinnehållet i praktiken inte skiljde sig nämnvärt åt mellan de två jämförda påföljderna.

Av de övriga nio studierna bygger en på mätning av antalet dagar $i$ anstalt före och efter vistelser utanför kriminalvårdsanstalt enligt § 34-institutet (Eriksson, m.fl. 1985). Förutom en rad brister är själva grunduppläggningen $i$ detta fall allt för tunn för att det ska vara möjligt att isolera effekter av behandlingen från effekter av andra tänkbara faktorer, exempelvis så kallad spontanläkning.

Resterande åtta undersökningar är framför allt behäftade med ett allvarligt gemen- 


\begin{tabular}{|c|c|c|c|c|}
\hline Författare & Intervention & Grunddesign & Effektvariabel & Huvudsaklig felkälla \\
\hline $\begin{array}{l}\text { Socialstyrelsen } \\
(1980)\end{array}$ & $\begin{array}{l}\text { Rättspsykiatrisk } \\
\text { vård }\end{array}$ & $\begin{array}{l}\text { Statisk } \\
\text { kontrollgrupp }\end{array}$ & $\begin{array}{l}\text { Återfall i brott } \\
\text { inom tre år }\end{array}$ & $\begin{array}{l}\text { De jämförda grupperna är } \\
\text { inte ekvivalenta }\end{array}$ \\
\hline $\begin{array}{l}\text { Caroli, R. m.fl. } \\
\text { (1982) }\end{array}$ & $\begin{array}{l}\text { Rättspsykiatrisk } \\
\text { vărd }\end{array}$ & $\begin{array}{l}\text { Statisk } \\
\text { kontrollgrupp }\end{array}$ & $\begin{array}{l}\text { Aterfall i brott } \\
\text { inom tre år }\end{array}$ & $\begin{array}{l}\text { De jämförda grupperna är } \\
\text { inte ekvivalenta }\end{array}$ \\
\hline $\begin{array}{l}\text { Ahlberg, K. } \\
\text { (1984) }\end{array}$ & $\begin{array}{l}\text { Internerings- } \\
\text { straff }\end{array}$ & $\begin{array}{l}\text { Statisk } \\
\text { kontrollgrupp }\end{array}$ & $\begin{array}{l}\text { Âterfall i brott } \\
\text { inom fem år }\end{array}$ & $\begin{array}{l}\text { Testningen simulerar, men } \\
\text { kan inte garantera, att de } \\
\text { jämförda grupperna är } \\
\text { ekvivalenta. }\end{array}$ \\
\hline $\begin{array}{l}\text { Lidberg, L. } \\
\text { (1985) }\end{array}$ & $\begin{array}{l}\text { Rättspsykiatrisk } \\
\text { vård }\end{array}$ & $\begin{array}{l}\text { Statisk } \\
\text { kontrollgrupp }\end{array}$ & $\begin{array}{l}\text { Aterfall i grova } \\
\text { sexualbrott inom } \\
\text { tre år }\end{array}$ & $\begin{array}{l}\text { De jämförda grupperna är } \\
\text { inte ekvivalenta }\end{array}$ \\
\hline $\begin{array}{l}\text { Eriksson, U-B. } \\
\text { m.fl. (1985) }\end{array}$ & $\S 34$-institutet & $\begin{array}{l}\text { För- och } \\
\text { eftermätning }\end{array}$ & $\begin{array}{l}\text { Antalet avtjänade } \\
\text { dagar } i \text { anstalt } \\
\text { under två } \\
\text { treårsperioder }\end{array}$ & $\begin{array}{l}\text { Ingen kontrollgrupp. } \\
\text { Metoden förmår inte att } \\
\text { kontrollera för historia } \\
\text { och mognad }\end{array}$ \\
\hline $\begin{array}{l}\text { Belfrage, H. } \\
\text { (1989) }\end{array}$ & $\begin{array}{l}\text { Rättspsykiatrisk } \\
\text { vård }\end{array}$ & $\begin{array}{l}\text { Statisk } \\
\text { kontrollgrupp }\end{array}$ & $\begin{array}{l}\text { Aterfall i brott } \\
\text { inom tre år }\end{array}$ & $\begin{array}{l}\text { De jämförda grupperna är } \\
\text { inte ekvivalenta }\end{array}$ \\
\hline $\begin{array}{l}\text { Andersson, T. \& } \\
\text { L. Alexandersson } \\
\text { (1994) }\end{array}$ & Samhällstjänst & $\begin{array}{l}\text { Statisk } \\
\text { kontrollgrupp }\end{array}$ & $\begin{array}{l}\text { Aterfall i brott } \\
\text { inom ett år }\end{array}$ & $\begin{array}{l}\text { De jämförda grupperna är } \\
\text { inte ekvivalenta }\end{array}$ \\
\hline $\begin{array}{l}\text { Statskontoret } \\
\text { (1992) }\end{array}$ & $\begin{array}{l}\text { Drogprojekt på } \\
\text { Österåker- } \\
\text { anstalten }\end{array}$ & $\begin{array}{l}\text { Matchad } \\
\text { kontrollgrupp }\end{array}$ & $\begin{array}{l}\text { Återfall i brott } \\
\text { inom fem år }\end{array}$ & $\begin{array}{l}\text { De jämförda grupperna är } \\
\text { inte ekvivalenta. Selektion } \\
\text { av motivation och } \\
\text { experimentell mortalitet }\end{array}$ \\
\hline $\begin{array}{l}\text { Törnros, J. } \\
(1992 ; 1993)\end{array}$ & $\begin{array}{l}\text { Påverkans- } \\
\text { program för } \\
\text { rattfylleridömda }\end{array}$ & $\begin{array}{l}\text { Matchad } \\
\text { kontrollgrupp }\end{array}$ & $\begin{array}{l}\text { Återfall i ratt- } \\
\text { fylleribrott inom } \\
\text { två och fyre år } \\
\end{array}$ & $\begin{array}{l}\text { De jämförda grupperna är } \\
\text { inte ekvivalenta. Selektion } \\
\text { av motivation }\end{array}$ \\
\hline $\begin{array}{l}\text { Fondén, C. } \\
\text { (1994) }\end{array}$ & $\begin{array}{l}\text { Ungdomsvård i } \\
\S 12 \text {-hem }\end{array}$ & $\begin{array}{l}\text { Matchad } \\
\text { kontrollgrupp }\end{array}$ & $\begin{array}{l}\text { Återfall i brott } \\
\text { inom } 20 \text { till } 31 \\
\text { månader }\end{array}$ & $\begin{array}{l}\text { De jämförda grupperna är } \\
\text { inte ekvivalenta. Ej möjligt } \\
\text { isolera eventuell } \\
\text { behandlingseffekt }\end{array}$ \\
\hline $\begin{array}{l}\text { Danielsen, T. \& } \\
\text { Y. Hammerlin } \\
(1995)\end{array}$ & $\begin{array}{l}\text { Påverkans- } \\
\text { program förr } \\
\text { rattfylleridömda }\end{array}$ & $\begin{array}{l}\text { Statisk } \\
\text { kontrollgrupp }\end{array}$ & $\begin{array}{l}\text { Áterfall i ratt- } \\
\text { fylleribrott inom } \\
\text { et och två och } \\
\text { ett halvt år }\end{array}$ & $\begin{array}{l}\text { De jämförda grupperna är } \\
\text { inte ekvivalenta. Selektion } \\
\text { av motivation }\end{array}$ \\
\hline
\end{tabular}

samt metodologiskt problem. Effektmätningen består i dessa fall av jämförelser mellan grupper som har blivit föremål för olika insatser. Problemet utgörs av att det i samtliga fall föreligger indikationer på att de jämförda grupperna inte var likvärdiga innan behandlingen, beträffande dimensioner som kan ha betydelse för återfallsbenägenheten. Därmed finns det en överhängande risk för att resultaten hänger samman med initiala olikheter som inte har med behandlingen att göra. De 
använda metoderna gör det inte möjligt att på ett övertygande sätt utesluta andra rimliga förklaringar till eventuella skillnader i återfall. Som exempel kan nämnas de fyra studierna som berör rättspsykiatrisk vård (Belfrage, 1989; Caroli, m.fl. 1982; Lidberg, 1985; Socialstyrelsen, 1985). I dessa fall jämförs personer som bedömts ha begått brotten under inflytande av psykisk sjukdom eller störning, med individer som i motsvarande utredning klassats som tillräckligt friska för att sona brotten på sedvanligt sätt. I stället för att kontrastera två initialt likvärdiga grupper bygger fördelningen till experiment- respektive kontrollgrupp på ett diskriminerande kriterium som kan ha väsentlig betydelse för tendensen till återfall. Det bör dock framhållas att undersökningarna av Caroli m.fl. och Lidberg inte uttryckligen utges för att vara effektstudier.

Effektstudien av samhällstjänst (Andersson \& Alexandersson, 1994) baseras, enligt uppgifter som presenteras i rapporten, också på jämförelser mellan två grupper som uppenbarligen inte var likvärdiga innan behandlingen. I de fall då matchning utnyttjats (Fondén, 1994; Statskontoret, 1992; Törnros, 1992; 1993) har denna metod inte förmått att kontrollera för de mest framträdande felkällorna, t.ex. selektion av motivation. I Statskontorets undersökning undergrävs trovärdigheten även av att avhopparna, av allt att döma huvudsakligen misslyckade fall, exkluderats från experimentgruppen. Värdet av Fondéns studie begränsas ytterligare av att det inte är möjligt att isolera eventuella effekter av den fokuserade behandlingen från den totala arsenalen av insatser som riktas mot de studerade ungdomarna. Utöver det så kallade jämförelseproblemet (Törnudd, 1969) innehåller samtliga undersökningar en rad fel och brister som ytterligare inskränker möjligheterna att betrakta dem som trovärdiga effektstudier.

\section{SLUTSATSER}

Slutsatserna formuleras med förbehåll för att relevanta undersökningar kan ha förbigåtts.

Mycket få effektstudier har genomförts i Norden under den aktuella perioden. Detta kan dels förklaras av att det finns få aktiva forskare inom brottsforskningen överhuvudtaget. Förhållandet kan även hänga samman med att praktiska och metodologiska problem verkar avskräckande på motiverade forskare.

Hela tio av elva närmare synade studier har svenskt ursprung. Detta beror troligen på att brottsforskningen är större i Sverige än i de övriga nordiska länderna, både $i$ ett absolut och ett relativt perspektiv. Vidare tycks effekter av behandling inte ha varit ett prioriterat område i övriga länder.

Endast två av de elva närmare granskade studierna bedöms som användbara för att bedöma effekter av behandling. Båda dessa undersökningar visar att de studerade insatserna inte hade några konstaterbara effekter på tendensen till återfall i brott. Det har alltså, med två undantag, inte producerats några användbara effektstudier i Norden mellan åren 1980 och 1995.

Problemet består framför allt $i$ att uppläggningarna och det övriga genomförandet inte gör det möjligt att betrakta de jämförda grupperna som likvärdiga innan be- 
handlingen. Resultaten kan mycket väl förklaras av skillnader i återfallsbenägenhet som förelåg redan innan behandlingen. Därtill är samtliga undersökningar behäftade med en rad andra brister.

Det finns alltså, med två undantag, inget trovärdigt empiriskt material som kan ligga till grund för bedömningar av vilka individualpreventiva effekter som insatser inom rättsväsendet har. De två undantagen berör verksamheter som inte hade någon effekt. Följaktligen går det inte att påstå att en påföljd har en mer positiv inverkan på tendensen till återfall än en annan. Inte heller är det möjligt att hävda att speciella behandlingsprogram minskar återfallsbenägenheten. Av detta kan man dra en viktig slutsats: det är inte möjligt att anta hypoteser om positiva effekter av behandling inom rättsväsendet utifrån modern nordisk behandlingsforskning. Det finns heller inga belägg för att vissa påföljder skulle ha en negativ inverkan på återfallet jämfört med andra straffrättsliga reaktioner.

Bristen på övertygande bevis för behandlingseffekter har betydelse för debatten om behandlingstankar kontra den nyklassiska rättsfilosofin. Utan konstaterbara effekter är det svårt att på ett övertygande sätt argumentera för det behandlingsinriktade idéalternativet. Det bör emellertid noteras att de nyklassiska idéerna måste prövas utifrån sina specifika antaganden och att man löpande måste beakta nya behandlingsrön från det vidare internationella forskningsfältet. Positiva erfarenheter från metadonbehandling gör exempelvis att det framstår som lämpligt att överväga att på prov införa denna behandlingsform i kriminalvården.

En erfarenhet från övrig kriminologisk forskning är att enskilda faktorer, exempelvis socioekonomisk status, ofta har liten relativ betydelse för variationer i brottslighet (se t.ex. Hagan, 1987). Därför är praktiker och forskare vanligtvis hänvisade till att utöva respektive undersöka företeelser som har förhållandevis liten inverkan på framtida kriminalitet. Det är emellertid ett känt faktum att ett litet antal förövare svarar för en stor andel av den totala kriminaliteten (Andersson, 1991; Wikström, 1987). Små behandlingseffekter skulle kunna få stor betydelse om de gällde dessa högaktiva brottslingar. Därför är det viktigt att forskningen lyckas fastställa eventuella effekter även om de kan tyckas vara små.

I de nordiska studier av behandlingseffekter som publicerats före år 1980 finns det exempel på relativt trovärdiga försök att hantera jämförelseproblemet (Bondeson, 1977; Börjesson, 1966; Christiansen m.fl. 1972; Kühlhorn, 1979; Uusitalo, 1971). Under senare har det blivit möjligt att använda en rad avancerade analystekniker, t.ex. händelseanalyser, logistisk regression och tidsserieanalyser med ARIMA (se t.ex. Allison, 1984; Arminger m.fl. 1995 respektive McCleary \& Hay, 1980). Dessa metoder har inte utnyttjats, eller använts på ett adekvat sätt, i den moderna behandlingsforskningen. Detta innebär att kvaliteten på forskningen har försämrats i stället för att utvecklas i takt med den ständigt pågående metodutvecklingen.

Även om det är omvittnat svårt är det naturligtvis inte omöjligt att åstadkomma tillförlitliga effektstudier. Ett antal övergripande förbättringar skulle kunna resultera i en väsentlig höjning av kunskapsnivån. En viktig aspekt är att ett ökat samarbete 
mellan myndigheter och forskare behöver komma till stånd. Detta skulle göra det möjligt att utnyttja starkare undersökningsuppläggningar, t.ex. slumpmässig fördelning till experiment- och kontrollgrupp vid frivilliga behandlingsinsatser. I en sådan situation skulle kunniga forskare i högre grad stimuleras att ge sig i kast med studier av behandllingseffekter. Nyfikna och samarbetsvilliga myndighetsrepresentanter kan alltså medverka till en vitalisering av behandlingsforskningen. Vidare kan forskningskvaliteten förbättras om tre grundläggande omständigheter beaktas. För det första måste forskarna ha tillräckliga kunskaper om de verksamheter de studerar. I annat fall finns det risk för att forskningen brister i verklighetsförankring. För det andra bör de instanser som utför forskningen vara oberoende av det operativa ansvaret för de undersökta verksamheterna. Myndigheter som utvärderar sin egen insats kan hämmas av hänsyn som gör att forskningen inte kan betraktas som trovärdig. För det tredje är det önskvärt att forskarnas arbete kvalitetskontrolleras i enlighet med god vetenskaplig sedvänja. Framför allt innebär detta att forskningens genomförande och genomslagskraft är beroende av bemötandet från en kompetent och kritiskt granskande omgivning. Om dessa önskemål kunde tillgodoses skulle det finnas bättre förutsättningar för att vinna insikter i vilka effekter som olika interventioner inom rättsväsendet har.

\section{LITTERATUR}

Ahlberg, K. (1984): Vanebrottslighet och påföljdsval, Stockholms Universitet, Sociologiska Institutionen.

Allison, P. (1984): Event History Analysis, Beverly Hills, Sage Publications. Andersson, J. (1991): Kriminella karriärer och påföljdsval, Stockholms Universitet, Sociologiska Institutionen, Project Metropolitan.

Andersson, T. \& L. Alexandersson (1994): Samhällstjänst som alternativ till fängelse: Utvärdering av 1990-1992 års försöksverksamhet, Stockholm, BRA PM 1994:3.

Andrews, D. A. m.fl. (1990): "Does correctional treatment work? A clinically relevant and psychologically informed meta-analysis", Criminology, 29, (3):369404.

Arminger; G. m.fl. (Red.) (1995): Handbook of Statistical Modeling for the Social and Behavioral Sciences, New York, Plenum Press.

Belfrage, H. (1989): Psykiskt störda brottslingar, Universitetet i Linköping.

Berggren, O. \& H. Svärd (1990): Österåkerprojektet - Uppföljning av budgetåren 1982-83 to m 1986-87, Kriminalvårdsstyrelsen (1990:2)

Bergmark, A. \& L. Oscarsson (1993): "Behandlingseffekter inom kriminalvården", I Effekter av offensiv narkomanvård, Stockholm, Socialstyrelsen följer upp och utvärderar 1993:1.

Bondeson, U. (1977): Kriminalvaird i frihet - Intention och verklighet, Stockholm, Liber Förlag.

Bondeson, U. (1986): "Frihetsberövandets verkningar", Nordisk Tidsskrift for Kriminalvidenskab, Vol. 73, No. 5: 415-425. 
Bondeson, U. (1987a): "Vetenskapsmetodik och kriminalpolitik", Nordisk Tidsskrift for Kriminalvidenskab, Vol. 74, No. 3: 269-277.

Bondeson, U. (1987b): "Slutreplik", Nordisk Tidsskrift for Kriminalvidenskab, Vol. 74, No. 4: 361-362.

Brå-rapport (1977): Nytt straffsystem: Idéer och förslag, Stockholm, Brå-rapport 1977:7.

Börjeson, B. (1966): Om påföljders verkningar, Stockholm, Almqvist \& Wiksell. Campbell, D. \& J. Stanley (1963): Experimental and Quasi-Experimental Designs for Research, Chicago, Rand McNally College Publishing Company.

Campbell, D. (1975): "Reforms as Experiments", i Struening \& Gutentag (Red.): Handbook of Evaluation Research, Vol. 1, Beverly Hills, Sage Publications.

Caroli, R. Smidelik, G. \& L. Öjesjö (1982): "Rättspsykiatriskt undersökta lagöverträdare och undersökningens följder III", Linköping, Statens rättspsykiatriska station (stencil).

Christiansen, K. Moe, M. \& L. Senholt (1972): Effektiviteten af forvaring og scerfengsel, København, Betænkning nr. 644.

Danielsen, T. \& Y. Hammerlin (1995): Fylla har skylda - En evaluering av promillekurset ved Hof arbeidskoloni, Kriminalomsorgens Utdanningssenter 1995:1. Eriksson, U-B. Gustavsson, J. Bishop, N. \& T. Pettersson (1985): \& 34 Lag om kriminalvård $i$ anstalt - Tillämpning av vistelser utanför anstalt, Kriminalvårdsstyrelsen 1985:1.

Fondén, C. (1994): "Jämförande studie av ungdomar som fick respektive inte fick plats på paragraf 12-hem 1990", Stockholms Universitet, C-Uppsats vid Kriminologiska Institutionen.

Grönbladh, L. \& L-M. Gunne (1989): "Methadone-assisted rehabilitation of Swedish heroin addicts", Drug and Alcohol Dependence, 24:31-37.

Grönbladh, L. Öhlund, L. S. \& L-M. Gunne (1990): "Mortality in addiction: impact of methadone treatment", Acta Psychiatrica Scandinavia, 82:223-227.

Gunne, L-M. \& L. Grönbladh (1980): "Metadonunderhållsbehandlingens effektivitet: En kontrollerad studie i narkomanvård", Läkartidningen, 4:227-230.

Hagan, J. (1987): Modern Criminology, Singapore, McGraw-Hill.

Kühlhorn, E. (1974): Effekter av behandling, Stockholms Universitet, Sociologiska Institutionen.

Kühlhorn, E. (1979): Frivård och rehabilitering, Stockholm, Brå Rapport 1979:3. Kühlhorn, E. (1986): "Allmänprevention och individualprevention", I Påföljdför brott, 3 Bilagor, Stockholm, SOU 1986:15.

Kühlhorn, E. (1987a): "Forskning, kriminalpolitik och verkligheten", Nordisk Tidsskrift for Kriminalvidenskab, Vol. 74, No. 3: 261-269.

Kühlhorn, E. (1987b): "Kommmentar", Nordisk Tidsskrift for Kriminalvidenskab, Vol. 74, No. 4: 360.

Kyvsgaard, B. (1978): Straffesystemets virkning: en redegørelse for undersøgelser over straffe- og behandlingsforanstaltningens effektivitet over for lovovertrcedere, Københavns Universitet. 
Lennéer-Axelson, B. \& I. Thylefors (1969): En individualterapeutisk effektstudie, Göteborgs Universitet, Psykologiska Institutionen.

Lidberg, L. (1985): "Sedlighetsbrott i Sverige: Påföljder; återfall och behandling",

Nordisk Tidsskrift for Kriminalvidenskab, Vol. 72. No. 1: 37-48.

Lipsey, M. (1991): "Juvenile delinquency treatment: A meta-analytic inquiry into the variabilitys of effects", I Cook, T. m.fl. (Red.): Meta-Analysis for Explanation: A Casebook, New York, Russel Sage Foundation.

Lipton, D. Martinsson, R. \& J. Wilks (1975): The Effectivness of Correctional Treatment: A Survey of Treatment Evaluation Studies, New York, Prager.

Mannheim, H. \& L. Wilkins (1955): Prediction Methods in Relation to Borstal Training, London, H.M.S.O.

McCleary, R. \& R. Hay Jr: (1980): Applied Time Series Analyses For the Social Sciences, Beverly Hills, Sage Publications.

Nachmias \& Nachmias (1991): Research Methods in the Social Sciences, London, Edward Arnold.

Parker, H. \& P. Kirby (1996): Methadone Maintenance and Crime Reduction on Merseyside, London, Home Office.

Pearson, F. Lipton, D. \& C. Cleland (1996): Some Preliminary Findings from The CDATE Project: A Paper Presented at the Annual Meeting of the American Society of Criminology, Chicago.

Socialstyrelsen (1980): Straff eller vård?, Stockholm, Socialstyrelsen redovisar 1980:3.

SOU (1986:15): Om straffskalor; påföljdsval, straffmätning och villkorlig frigivning $m m$., Stockholm, Almänna Förlaget.

SOU (1995:91): Ett reformerat straffsystem, Stockholm, Fritzes.

Statskontoret (1992): Effekter av Kriminalvård: En utvärdering av narkotikaprojektet på Österåker, Stockholm, Statskontoret.

Törnros, J. (1992): Rattfällan: Utvärdering av kurs för fängelsedömda rattfyllerister; Linköping, Väg- och trafikinstitutet, VTI-Rapport.

Törnros, J. (1993): Rattfällan: Utvärdering av kurs för fängelsedömda rattfyllerister - återfall inom en fyra-årsperiod, Linköping, Väg- och transportforskningsinstitutet, VTI-Rapport.

Törnudd, P. (1969): Fylleriböter som medel för social kontroll, Helsingfors, Kriminologiska forskningsinstitutet.

Uusitalo, P. (1972): "Recidivism after release from closed and open penal institutions", British Journal of Criminology, 12, 211-229.

Whitehead, J. \& S. Lab (1989): "A Meta-analysis of Juvenile Correctional Treatment", Journal of Research in Crime and Delinquency, 26, (3), 276-295. Wikström, P-O. (1987): Patterns of Crime in a Birth Cohort -Age, Sex, and Social Class Differences, Stockholms Universitet, Sociologiska Institutionen Project Metropolitan. 
Adress: Erik Grevholm \& Eckart Kühlhorn

Sociologiska Institutionen

Stockholms Universitet

S-106 91 Stockholm

Sverige

Tel: +468163168

Fax: +46816125580

E-mail: kuhlhorn@sociology.su.se 